\title{
Trait stacking for biotech crops: an essential consideration for agbiotech development projects for building trust
}

\author{
Obidimma C Ezezika ${ }^{1,2^{*}}$, Nadira Saleh ${ }^{1}$ and Abdallah S Daar ${ }^{1,3}$
}

\begin{abstract}
The development of agricultural biotechnology humanitarian projects for food security in the last five years has been rapid in developing countries and is expected to rise sharply over the coming years. An extremely critical issue in these projects involves building trust with the community and farmers they aim to serve. For the first time, our social audit engagement with one of these initiatives, the Water Efficient Maize for Africa project, has revealed that a critical but unrecognized component of building trust with farmers involves publicly addressing the concerns surrounding stacked trait crops. As a result, we argue in this article that it is critical to actively anticipate the concerns that could be raised over trait stacking by incorporating them into global access plans of such initiatives early in order to facilitate adoption, provide the best value to the small-scale farmer and gain trust with the community whom these projects aim to serve. This perspective, based on an actual international social audit, should be of value to scientists, funders and partners involved in biotech development initiatives for food security.
\end{abstract}

Keywords: stacked trait crops, trust, GM crops, biotechnology, maize, social audit

\section{Introduction}

Publicly addressing the concerns over stacked trait crops early on in biotech development initiatives provides great potential to generate mutually advantageous solutions for all partners and stakeholders, enhance opportunities to build trust, and increase the likelihood that the initiative will succeed. We make this proposition based on our experience with the Water Efficient Maize for Africa (WEMA) project, which is a public-private partnership (PPP) working to develop drought-tolerant, royalty-free African maize varieties for small-scale farmers in subSaharan Africa using a combination of conventional and marker-assisted breeding and transgenic technology.

The term 'trait stacking' for genetically modified (GM) or biotech crops refers to the incorporation of multiple genetic modifications, or traits, in a single variety of a crop [1]. Crops with stacked traits are more effective at meeting the needs of farmers and consumers than the traditional,

\footnotetext{
* Correspondence: obidimma.ezezika@srcglobal.org

'Sandra Rotman Centre, University Health Network and University of Toronto,

101 College Street, Toronto, ON, M5G 1L7, Canada

2Dalla Lana School of Public Health, University of Toronto, Toronto, Ontario, Canada

Full list of author information is available at the end of the article
}

mono-trait seed varieties because they allow for a product to be modified for multiple traits concurrently such as tolerance to herbicides, resistance to insects and improved nutritional content [2].

The first stacked crop to be fully commercialized was a cotton seed that was produced using patented genes owned and developed by Monsanto, a multinational agricultural biotechnology company. These incorporated genes provide protection against certain pests and enable the use of the herbicide glyphosate [1]. The case of this cotton seed has been followed by the commercialization of other crops with stacked traits such as the Agrisure ${ }^{\circledR}$ 3000GT which protects against corn borer and corn rootworm while providing tolerance to in-season applications of certain herbicides [3]. A total of 42.2 million hectares of stacked biotech crops were planted in 2011, compared to 32.2 million hectares in 2010.

The WEMA project engages a number of stakeholders from both the public and private sector, including the African Agricultural Technology Foundation (AATF); the International Maize and Wheat Improvement Center (CIMMYT); the Monsanto company; and five National Agricultural Research Systems (NARS) in Kenya, Tanzania, South Africa, Uganda and Mozambique [4]. In 
2009, the Sandra Rotman Centre in Toronto, Canada conducted a social audit of the WEMA project, which is funded by the Bill \& Melinda Gates Foundation [5]. A social audit is a process whereby an audit team collects and analyses information from stakeholders in order to produce an account of a project's ethical, social and cultural performance and impact.

The findings of the social audit revealed that, despite the many examples of stacked trait crops being commercialized, they are not regularly considered in agbiotech projects for humanitarian purposes. Based on the unique findings from our audit, we posit that agricultural development projects must anticipate the concerns that could be raised over trait stacking and incorporate them into their project plans early in order to build trust with stakeholders.

\section{Addressing trait stacking early builds trust}

The goal of the social audit was to discover and address barriers to building trust in agricultural development initiatives, such as the WEMA project, as a means to ensure the best project outcomes for the small-scale farmer. Public-private partnerships involved in agbiotech projects face issues of public distrust due to concerns surrounding the use of transgenic technology and the complex nature of these partnerships, which comprise organizations with varied interests and priorities. As such, PPPs engaged in agbiotech projects may sometimes face public scrutiny or experience a lack of trust due to diverse points of view, such as those contextualized by ethical, social, cultural or commercialization concerns [6].

This lack of trust poses a significant risk to the humanitarian goals of such projects. This risk could be exacerbated if important issues relevant to building trust among project partners and the public are not appropriately addressed at an early stage in project development.

A barrier to establishing trust, as identified by project stakeholders in the social audit of the WEMA project, was the issue of trait stacking [2]. These stakeholders comprise of farmers, managers of seed companies, biosafety regulators, scientists, legal consultants and other experts in the agricultural development sector. They noted that that publicly and transparently addressing concerns around stacked traits is necessary and productive when developing agbiotech projects. This would mitigate various concerns that stakeholders have, such as worry that the project could be a potential ploy for private companies to gain access to the African market. Environmental groups such as Greenpeace have dubbed such projects 'Trojan horses', asserting that these projects are merely another means for large biotech companies to extend their GM market base especially as technology allows for further trait stacking [7].

\section{Stacked traits also facilitate adoption of biotech crops}

Although the goal of creating the WEMA variety is to provide a low-cost, royalty-free variety of drought-tolerant maize to small-scale farmers, our social audit panelists have indicated that it will be difficult to ensure adoption without other critical traits.

Stacked traits are becoming an increasingly important feature of biotech crops, and farmers are beginning to recognize the benefits of including stacked crops in their farming practices [2]. In 2011, biotech crops were planted by twelve countries, nine of which were developing countries. In the same year, stacked double- and triple-traits occupied $26 \%$ of the global biotech land area [8]. These events suggest that drought-tolerant seeds that are not stacked with important traits are unlikely to be adopted, especially if other seeds with these significant characteristics are available.

Stacked crops represent important upcoming technologies for farmers. In general, when the needs of farmers are considered in the development of crops, the likelihood of them adopting such crops is greater. This is reflected by the increased rate of adoption of crops with stacked traits over the last few years [2].

\section{Overcoming constraints: cost and multiple-partner engagement}

If publicly addressing concerns about stacked traits in humanitarian projects is valuable in building public trust and eventually facilitating adoption, it is surprising that the use of stacked traits has yet to be considered and publicly addressed in the early stages of these projects. We believe that this is due to two challenges: concern with cost-effectiveness and enabling multi-partner engagement. These constraints can be easily overcome, however. For example, one of the projects under the Grand Challenges in Global Health of the Gates Foundation is the Golden Rice project, which is designed to engineer rice for increased levels of beta carotene (vitamin A precursor), vitamin E, and enhanced iron (Fe) and zinc ( $\mathrm{Zn})$ bioavailability [9]. The engineered rice, targeted to the poor in developing countries, is perhaps one of the most well-known GM varieties in development, and has been successful in overcoming the challenge of maintaining cost-effectiveness through the use of a humanitariandefined license [10]. The project negotiated access to all necessary patents from companies including Bayer AG, Monsanto, Novartis AG, Orynova BV, and Zeneca Mogen BV - all of whom agreed to provide access to their technologies free of charge for a defined humanitarian purpose, making end-user licensing relatively uncomplicated $[11,12]$.

In addition to the issue of cost-effectiveness is the challenge of engaging multiple seed companies, as individual 
companies may own patents to different traits that may need to be incorporated into a single product. However, the complexities of multi-stakeholder involvement are not unprecedented when it comes to agbiotech initiatives. Maize with stacked traits acquired from multiple companies has been successfully developed and implemented in the past. For example, in 2007, Agrisure ${ }^{\circledR}$ 3000GT, a triple-stack maize hybrid that protects against both corn borer and corn rootworm, was developed. It includes traits that are owned by different companies and is marketed by Syngenta through a licensing agreement with Monsanto [1,13]. Additionally, both companies have granted external companies [including competitors] stacking rights to their traits. Although admittedly complex, the Agrisure $^{\circledR} 3000 G \mathrm{~T}$ is an example that highlights the ability of industry competitors to effectively incorporate their respective biotechnologies into a single end product.

\section{Conclusions}

The concerns raised over the use of stacked traits as uniquely revealed by our social audit of the WEMA project are applicable to other current and upcoming agbiotech projects. Principal investigators and funders of humanitarian agbiotech initiatives should actively anticipate these concerns and incorporate them into their project plans in order to gain trust with the community they aim to serve. Although issues such as cost-effectiveness and the engagement of multiple project partners may be perceived as constraints to incorporating the use of stacked traits in agbiotech development projects, cases such as the Golden Rice project and Agrisure ${ }^{\circledR}$ 3000GT demonstrate that such obstacles can be overcome, especially if project partners commit to maintaining a humanitarian focus. We believe that publicly addressing concerns surrounding stacked traits early in biotech development initiatives will increase the potential of all partners and stakeholders to generate mutually advantageous solutions and enhance opportunities to build trust.

\section{Acknowledgements}

We are grateful to Jocalyn Clark and Lauren Daley for their comments on earlier drafts of the manuscript. This research was funded by the Bill \& Melinda Gates Foundation. The findings and conclusions contained within are those of the authors and do not necessarily reflect official positions or policies of the Foundation.

\section{Author details \\ 'Sandra Rotman Centre, University Health Network and University of Toronto, 101 College Street, Toronto, ON, M5G 1L7, Canada. Dalla Lana School of Public Health, University of Toronto, Toronto, Ontario, Canada. ${ }^{3}$ Dalla Lana School of Public Health Sciences and Department of Surgery, University of} Toronto, Toronto, Ontario, Canada.

\section{Authors' contribution}

OCE conceived of the study and participated in its design and coordinated and drafted the manuscript. NS conducted a literature review of stacked traits and helped draft the manuscript. ASD participated in the design and helped draft the manuscript. All authors read and approved the manuscript.
Received: 22 November 2011 Accepted: 21 May 2012

Published: 21 May 2012

\section{References}

1. Sorting out the facts behind stacks., [https://www.monsanto.com/ newsviews/Pages/gene-stacks-facts.aspx].

2. James C: Global status of commercialized biotech/GM crops. ISAAA 2010, Brief No. 42

3. SeedQuest: Syngenta's Agrisure 3000GT quad stack available for 2008 planting season in the U.S., [http://www.seedquest.com/News/releases/ 2007/august/20087.htm].

4. African Agricultural Technology Foundation: Project 4: Water Efficient Maize for Africa (WEMA)., [http://www.aatf-africa.org/userfiles/WEMA-brief. pdf].

5. Ethical, Social, Cultural and Commercialization Program: WEMA 2009 social audit report: ethical, social, cultural and commercialization audit report for the Water Efficient Maize for Africa Project, 2009. 2010, [http://www. aatf-africa.org/userfiles/WEMA-2009-Audit\%20Report_2010.pdf].

6. Ezezika OC, Daar AS, Barber K, Mabeya J, Thomas F, Deadman J, Wang D, Singer PA: Factors influencing agbiotech adoption and development in sub-Saharan Africa. Nat Biotechnol 2012, 30:38-40.

7. Schiermeier Q: Designer rice to combat diet deficiencies makes its debut. Nature 2001, 409:551(551).

8. James C: Executive summary: global status of commercialized biotech/ GM crops: 2011. ISAAA 2011, . Brief No. 43.

9. Beyer $P$ : Engineering rice for high beta carotene, vitamin $E$ and enhanced fe and zn bioavailability., [http://www.grandchallenges.org/ImproveNutrition/ Challenges/NutrientRichPlants/Pages/Rice.aspx\#Collaborators].

10. ProVitaMinRice consortium: Grand Challenges in Global Health Project. [http://www.goldenrice.org/Content5-GCGH/GCGH1.html].

11. Golden Rice Humanitarian Board: intellectual property-related issues: a public-private partnership and humanitarian licences., [http://www. goldenrice.org/Content2-How/how9_IP.html].

12. Krattinger A, Potrykus I: Golden rice: a product-development partnership in agricultural biotechnology and humanitarian licensing. In Executive guide to intellectual property management in health and agricultural innovation: a handbook of best practices. Edited by Krattinger A, Mahoney RT, Nelsen L. Davis: PIPRA; 2007.

13. Stein AJ, Rodriguez-Cerezo E: The global pipeline of new GM crops: implications for asynchronous approval for international trade. 2009. Report No. EUR 23846 EN.

doi:10.1186/2048-7010-1-5

Cite this article as: Ezezika et al: Trait stacking for biotech crops: an essential consideration for agbiotech development projects for building trust. Agriculture and Food Security 20121:5.

\section{Submit your next manuscript to BioMed Central and take full advantage of:}

- Convenient online submission

- Thorough peer review

- No space constraints or color figure charges

- Immediate publication on acceptance

- Inclusion in PubMed, CAS, Scopus and Google Scholar

- Research which is freely available for redistribution 